\title{
DESENVOLVIMENTO SUSTENTÁVEL E EMPREENDEDORISMO
}

Emmanuel Raufflet - HEC Montréal ${ }^{1}$

Luc Bres - Université Paris Dauphine ${ }^{2}$

Louis Jacques Filion - HEC Montréal ${ }^{3}$

Resumo: Esta revisão de pesquisas sobre desenvolvimento sustentável e empreendedorismo (EDS) busca identificar os conceitos-chaves e examinar o conhecimento atual neste campo, tais como as razões para a emergência do EDS, o perfil dos novos empreendedores (ED - empreendedores em desenvolvimento sustentável), as especificidades dos processos de gestão e os novos setores de atividades ligadas ao EDS. Esta revisão dos principais estudos nesta temática em emergência conclui sugerindo caminhos para pesquisas futuras.

Palavras-chave: desenvolvimento sustentável, empreendedorismo, empreendedorismo ecológico, mercados verdes.

\section{SUSTAINABLE DEVELOPMENT AND ENTREPRENEURSHIP}

Abstract: The purpose of this literature review on the emerging field of sustainable development and entrepreneurship (SDE) is to identify key concepts and to examine current knowledge, including the reasons for the emergence of SDE, new entrepreneur profiles, management process features and new SDE-related activity sectors. The paper concludes with some future research avenues.

Keywords: sustainable development, entrepreneurship, ecological entrepreneurship, green markets.

\section{Introdução}

O campo do empreendedorismo se interessa cada vez mais pelo desenvolvimento sustentável. Em razão disso, este artigo propõe um levantamento dos estudos da área a partir da análise de mais de cem textos publicados entre 1992 e 2008 (ver seção de metodologia). Esta revisão de literatura está organizada em seis seções. A primeira trata do que é o desenvolvimento sustentável e o empreendedorismo e busca definir e nomear as noções e conceitos-chaves. A segunda seção se concentra sobre o porquê do desenvolvimento sustentável e do empreendedorismo sob dois pontos de vista: (1) o econômico, que explica a

\footnotetext{
${ }^{1}$ E.mail: emmanuel.raufflet@hec.ca Endereço: 3000 Chemin de la Côte-Sainte-Catherine, Montreal, QC H3T 2A7, Canadá

2 E.mail: luc.bres@gmail.com

${ }^{3}$ E.mail: louisjacques.filion@hec.ca
}

RAUFFLET, E.; BRES, L.; FILION, L. J. Desenvolvimento sustentável e empreendedorismo. Revista de Empreendedorismo e Gestão de Pequenas Empresas, v. 3, n.1, p.3-32, 2014. 
emergência dos empreendedores sustentáveis em razão das deficiências de mercado; e (2) o das motivações, características e percursos individuais dos empreendedores. A terceira seção mapeia quem atua neste campo, a partir da literatura que trata da tipologia dos empreendedores (entre casos) e dos estudos de casos individuais (intracasos). A quarta seção se concentra sobre os processos de gestão e de inovação ligados ao desenvolvimento sustentável e ao empreendedorismo, ou seja, o como. A quinta seção discute sobre os novos setores de aplicação do empreendedorismo ligado ao desenvolvimento sustentável, isto é, o onde. Como conclusão, a última seção aponta caminhos de pesquisa para este campo em formação. Em suma, este artigo essencialmente retoma uma reflexão anterior sobre esta temática (BRES; RAUFFLET; FILION, 2011).

\section{Metodologia da revisão crítica da literatura}

Esta revisão crítica da literatura foi realizada no fim de 2008. Foram utilizados bancos de dados ABI/Inform Global, Business Source Complete, Science direct, Kluwer Online e a revista internacional PME. Para cada uma dessas bases de dados foram utilizadas palavras-chave: sustainable entrepreneur, sustainable entrepreneurship, ecopreneur e green entrepreneur. Exceto por ecopreneur, que não é uma palavra composta, sempre que possível foi utilizado o operador de proximidade para garantir que os textos encontrados correspondessem às palavras compostas e não unicamente às palavras individuais. As buscas foram realizadas sobre os campos título, resumo e palavras-chave.

Antes da importação, os textos cujos títulos eram evidentemente muito afastados do tema foram eliminados. Desta forma, foram obtidos pouco mais de 100 artigos relacionados com a presente pesquisa, dos quais cerca de 60 eram artigos acadêmicos. Como complemento, os capítulos teóricos do livro Making Ecopreneurs: Developing Sustainable Entepreneurship (SCHAPER, 2005) (parte 1) foram analisados juntamente com as suas respectivas bibliografias. Todos os artigos acadêmicos foram revisados por completo, enquanto que, para os artigos obtidos da imprensa, frequentemente foram revisados apenas os resumos. 
Um pouco menos de dois terços dos textos obtidos foram artigos de natureza descritiva que, na maioria das vezes, examinavam casos de sucesso em desenvolvimento sustentável (entre os artigos mais recentes: ACTOR, 2008; NEW REPORT, 2008; WIDE, 2008; GARMHAUSEN; JOHNSON; DELANEY, 2008; JEKWA, 2008; LEE, 2008; WARNOCK, 2008). Pouco mais de um terço dos textos restantes foram de natureza mais teórica. Por fim, um sexto dos textos foram de natureza prescritiva, oferecendo recomendações para empreendedores em desenvolvimento sustentável. Evidentemente, alguns textos podiam apresentar diversas dimensões, sendo ao mesmo tempo descritivos, teóricos e prescritivos.

\section{O quê: definição e nomenclatura do desenvolvimento sustentável e do empreendedorismo}

O campo do desenvolvimento sustentável é um campo em emergência e em plena ebulição. Ao longo das últimas décadas numerosas pesquisas evidenciaram o caráter não sustentável das interações entre as sociedades humanas e a biosfera. A emergência do campo do empreendedorismo sustentável é ainda mais recente, sendo produto da intersecção de dois campos relativamente novos: desenvolvimento sustentável e empreendedorismo. Este cruzamento corresponde ao surgimento de uma nova categoria de empreendedores comuns em certas formas de empreendedorismo cooperativo, empreendedorismo filantrópico e, principalmente de empreendedorismo social, como o das organizações sem fins lucrativos. Nos debates acadêmicos, os conceitos de empreendedor ambiental (LINNANEN, 2002), empreendedor verde (WALLEY; TAYLOR, 2002; BERCHICCI, 2005), empreendedor ecológico (MARSDEN; SMITH, 2005), ecoempreendedor (PASTAKIA, 1998; ISAAK, 2002; SCHALTEGGER, 2002; DIXON; CLIFFORD, 2007) e empreendedor em desenvolvimento sustentável (COHEN; WINN, 2007; DEAN; MCMULLEN, 2007; KATSIKIS; KYRGIDOU, 2007; CHOI; GRAY, 2008) são conceitos bastante próximos. As demarcações entre cada um destes conceitos são tênues, às vezes praticamente inexistentes, e os autores se referem às mesmas práticas, porém apresentando-as sob diferentes ângulos e vocábulos. A emergência desse novo campo aconteceu nos anos 1990 e foi se desenhando gradualmente ao longo 
da mesma década. Mas, esta ebulição não se dá sem confusão, por meio de ciclos mais ou menos intensos, e tem uma retomada marcante na virada do novo milênio (SCHAPER, 2005). Uma seleção de definições-chave, presentes em publicações científicas de 1998 a 2008, é apresentada no Quadro 1.

Quadro 1: Principais definições do ecoempreendor e do empreendedor em desenvolvimento sustentável nos anos 2000

\begin{tabular}{|c|c|c|c|c|c|c|c|}
\hline Ano & $\begin{array}{c}\text { Discipl } \\
\text { ina }\end{array}$ & Autor & $\begin{array}{l}\text { Periódi } \\
\text { co }\end{array}$ & $\begin{array}{c}\text { Termo } \\
\text { definid } \\
0\end{array}$ & $\begin{array}{c}\text { Conceito } \\
\text { associad } \\
0\end{array}$ & Definição & $\begin{array}{c}\text { Exemplo } \\
s\end{array}$ \\
\hline 1998 & $\begin{array}{l}\text { Gestão } \\
\text { e } \\
\text { Empre } \\
\text { en- } \\
\text { dedoris } \\
\text { mo }\end{array}$ & $\begin{array}{c}\text { Pastak } \\
\text { ia }\end{array}$ & $\begin{array}{c}\text { Journal } \\
\text { of } \\
\text { Organiz } \\
\text { a-tional } \\
\text { Change } \\
\text { Manage } \\
\text { ment }\end{array}$ & $\begin{array}{l}\text { Ecoemp } \\
\text { reen- } \\
\text { dedor }\end{array}$ & $\begin{array}{l}\text { Ecoempr } \\
\text { een- } \\
\text { dedor/defi } \\
\text { ciên-cia } \\
\text { de } \\
\text { mercado }\end{array}$ & $\begin{array}{l}\text { "Indivíduos ou } \\
\text { instituições que tentam } \\
\text { popularizar ideias eco- } \\
\text { amigáveis e inovações } \\
\text { por meio do mercado ou } \\
\text { do não-mercado pode } \\
\text { ser referido como } \\
\text { ecoempreendedor" }\end{array}$ & $\begin{array}{c}\text { Jambheka } \\
r \\
\text { (Fertilizan } \\
\text { tes } \\
\text { alternativo } \\
\text { s na } \\
\text { Índia) }\end{array}$ \\
\hline 2002 & $\begin{array}{l}\text { Gestão } \\
\text { Interna } \\
\text {-cional }\end{array}$ & Isaak & $\begin{array}{l}\text { Greener } \\
\text { Manage } \\
\text { ment } \\
\text { Internati } \\
\text { onal }\end{array}$ & $\begin{array}{l}\text { Ecoemp } \\
\text { reen- } \\
\text { Dedor }\end{array}$ & $\begin{array}{c}\text { Ecoempr } \\
\text { een- } \\
\text { dedorism } \\
\text { o/ } \\
\text { ideal } \\
\text { weberian } \\
\text { o }\end{array}$ & $\begin{array}{c}\text { "a pessoa que busca } \\
\text { transformar um setor da } \\
\text { economia em direção à } \\
\text { sustentabilidade por } \\
\text { meio do lançamento de } \\
\text { negócios em setor com } \\
\text { design verde, processos } \\
\text { verdes e com } \\
\text { comprometimento de } \\
\text { longo prazo com a } \\
\text { sustentabilidade em tudo } \\
\text { que é dito e feito" }\end{array}$ & $\begin{array}{l}\text { Jerry } \\
\text { Greenfield } \\
\text { (Ben \& } \\
\text { Jerry's) } \\
\\
\text { Anita } \\
\text { Roddick } \\
\text { (Body } \\
\text { Shop) }\end{array}$ \\
\hline 2002 & $\begin{array}{c}\text { Gestão } \\
\text { Ambie } \\
\text { ntal }\end{array}$ & $\begin{array}{l}\text { Schalt } \\
\text { egger }\end{array}$ & $\begin{array}{l}\text { Greener } \\
\text { Manage } \\
\text { ment } \\
\text { Internati } \\
\text { onal }\end{array}$ & $\begin{array}{l}\text { Ecoemp } \\
\text { reen- } \\
\text { dedor }\end{array}$ & $\begin{array}{l}\text { Ecoempr } \\
\text { een- } \\
\text { dedorism } \\
\text { o e } \\
\text { gestão } \\
\text { ambiental }\end{array}$ & $\begin{array}{l}\text { "atores e empresas } \\
\text { fazendo do progresso } \\
\text { ambiental seu negócio } \\
\text { pode ser chamada de } \\
\text { ecoempreendedora" }\end{array}$ & $\begin{array}{c}\text { Claus } \\
\text { Hipp } \\
\text { Hipp } \\
\text { Company } \\
\text { (comida } \\
\text { para } \\
\text { bebês) }\end{array}$ \\
\hline 2002 & $\begin{array}{c}\text { Gestão } \\
\text { Ambie } \\
\text { ntal } \\
\text { (Walley } \\
\text { ) e } \\
\text { empre } \\
\text { endedo } \\
\text { rismo } \\
\text { (Taylor } \\
\text { ) }\end{array}$ & $\begin{array}{l}\text { Walley } \\
; \\
\text { Taylor }\end{array}$ & $\begin{array}{l}\text { Greener } \\
\text { Manage } \\
\text { ment } \\
\text { Internati } \\
\text { onal }\end{array}$ & $\begin{array}{l}\text { Empree } \\
\text { en- } \\
\text { dedor } \\
\text { verde }\end{array}$ & $\begin{array}{l}\text { Ecoempr } \\
\text { eeen- } \\
\text { dedor/Em } \\
\text { preen- } \\
\text { dedor } \\
\text { verde }\end{array}$ & $\begin{array}{l}\text { Propõe compreender o } \\
\text { ecoempreendedor em } \\
\text { referência a Isaak (2002) } \\
\text { e distinguir um } \\
\text { empreendedor verde, } \\
\text { com base na oposição } \\
\text { entre negócios verdes } \\
\text { (green business) e } \\
\text { negócios verdes verdes } \\
\text { (green green business): } \\
\text { "Neste artigo } \\
\text { argumentamos que a }\end{array}$ & $\begin{array}{l}\text { Jerry } \\
\text { Greenfield } \\
\text { (Ben \& } \\
\text { Jerry's) } \\
\\
\text { Anita } \\
\text { Roddick } \\
\text { (Body } \\
\text { Shop) }\end{array}$ \\
\hline
\end{tabular}

RAUFFLET, E.; BRES, L.; FILION, L. J. Desenvolvimento sustentável e empreendedorismo. Revista de Empreendedorismo e Gestão de Pequenas Empresas, v. 3, n.1, p.3-32, 2014. 


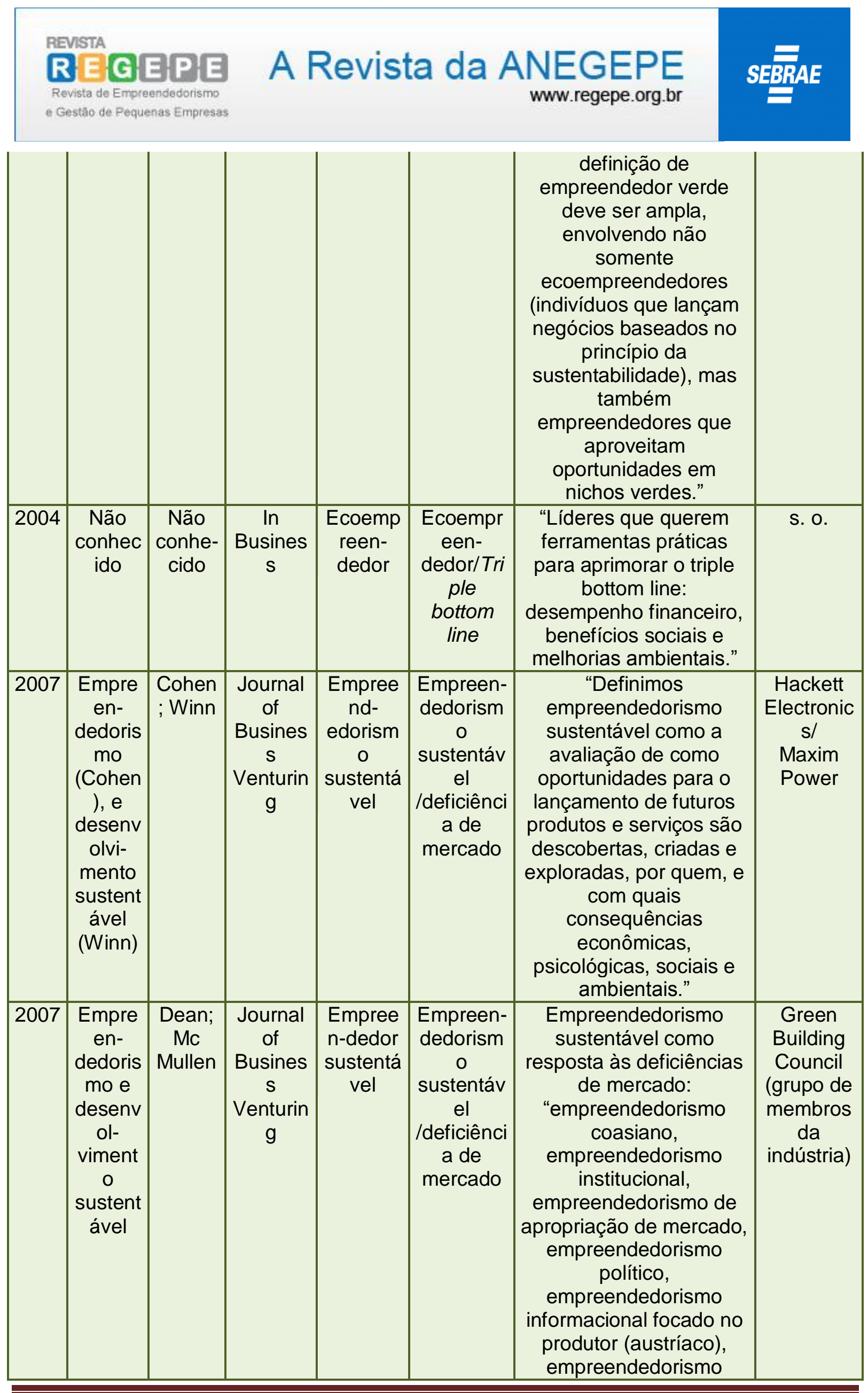

RAUFFLET, E.; BRES, L.; FILION, L. J. Desenvolvimento sustentável e empreendedorismo. Revista de Empreendedorismo e Gestão de Pequenas Empresas, v. 3, n.1, p.3-32, 2014. 


\begin{tabular}{|c|c|c|c|c|c|c|c|}
\hline & & & & & & $\begin{array}{l}\text { informacional focado no } \\
\text { cliente" }\end{array}$ & \\
\hline 2007 & $\begin{array}{l}\text { Não } \\
\text { conhec } \\
\text { ido }\end{array}$ & $\begin{array}{l}\text { Dixon; } \\
\text { Cliffor } \\
\quad d\end{array}$ & $\begin{array}{c}\text { Journal } \\
\text { of } \\
\text { Organiz } \\
\text { ati-onal } \\
\text { Change } \\
\text { Manage } \\
\text { ment }\end{array}$ & $\begin{array}{c}\text { Ecoemp } \\
\text { reen- } \\
\text { dedoris } \\
\text { mo }\end{array}$ & $\begin{array}{l}\text { Ecoempr } \\
\text { eeen- } \\
\text { dedor/tripl } \\
\text { e bottom } \\
\text { line }\end{array}$ & $\begin{array}{c}\text { A palavra } \\
\text { ecoempreendedor é, } \\
\text { portanto, utilizada neste } \\
\text { trabalho para } \\
\text { representar os três } \\
\text { drivers desses } \\
\text { indivíduos: ambiental, } \\
\text { social e econômico. } \\
\text { (definição inspirada em } \\
\text { Isaak) }\end{array}$ & $\begin{array}{c}\text { Colin } \\
\text { Crooks, } \\
\text { Green- } \\
\text { Works }\end{array}$ \\
\hline 2007 & Gestão & $\begin{array}{l}\text { Katsiki } \\
\text { s; } \\
\text { Kyrgi- } \\
\text { Dou }\end{array}$ & $\begin{array}{c}\text { Academ } \\
\text { y of } \\
\text { Manage } \\
\text { ment } \\
\text { Proceed } \\
\text { ings }\end{array}$ & $\begin{array}{c}\text { Empree } \\
n- \\
\text { dedoris } \\
\text { mo } \\
\text { sustentá } \\
\text { vel }\end{array}$ & $\begin{array}{l}\text { Empreen- } \\
\text { dedorism } \\
0 \\
\text { sustentáv } \\
\text { el }\end{array}$ & $\begin{array}{l}\text { "o processo teleológico } \\
\text { visando a realização do } \\
\text { desenvolvimento } \\
\text { sustentável, por meio da } \\
\text { descoberta, avaliação e } \\
\text { exploração de } \\
\text { oportunidades e criação } \\
\text { de valor, que produz a } \\
\text { prosperidade } \\
\text { econômica, coesão } \\
\text { social e proteção } \\
\text { ambiental." }\end{array}$ & $\begin{array}{c}\text { Chios } \\
\text { Gum } \\
\text { Mastic, } \\
\text { Greeks } \\
\text { Growers } \\
\text { (cooperati } \\
\text {-vas) }\end{array}$ \\
\hline
\end{tabular}

Fonte: Elaborado pelos autores

Esta lista revela a multiplicidade, um pouco problemática, de conceitos que fazem mais ou menos referência à noção de desenvolvimento sustentável e empreendedorismo. De fato, até os anos 2000 , os diferentes conceitos que vieram a designar os empreendedores engajados em desenvolvimento sustentável foram empregados de maneira relativamente intercambiada e suas definições eram bastante amplas. Elas se referiam geralmente a indivíduos preocupados com o meio ambiente e, algumas vezes, com as repercussões sociais de suas atividades (PASTAKIA, 1998; CHOI; GRAY, 2008). Por outro lado, a partir dos anos 2000, duas tendências pareceram se configurar, tendo de um lado o ecoempreendedor e do outro o empreendedor em desenvolvimento sustentável. 


\section{Ecoempreendedor ou empreendedor em desenvolvimento sustentável? ${ }^{4}$}

De acordo com Filion e Lima (2010), o estudo do empreendedorismo pode ser feito a partir de diferentes perspectivas, uma delas envolve as características dos atores empreendedores. Estes atores geram novas contribuições que trazem novidades com diferenciação e com valor agregado em comparação ao que já existia, em outras palavras, inovação. Na relação entre empreendedorismo e desenvolvimento sustentável, os atores podem ser chamados de ecoempreendedores ou empreendedores em desenvolvimento sustentável. Sendo que, os conceitos de ecoemprendedor ou de empreendedor verde são similares e mais antigos que o conceito de empreendedor em desenvolvimento sustentável.

Os autores que, desde o início dos anos 1990, falam de ecoempreendedores se concentram mais frequentemente nas análises de casos, particularmente biografias ou análises de boas práticas (PASTAKIA, 1998; DIXON; CLIFFORD, 2007) que permitem evidenciar as motivações e éticas desses empreendedores e as técnicas de gestão que eles desenvolvem para servir aos seus objetivos (PASTAKIA, 1998; ISAAK, 2002; SCHALTEGGER, 2002; DIXON; CLIFFORD, 2007). Em um nível epistemológico, estes estudos valorizam de maneira normativa estes empreendedores: eles são apresentados mais ou menos explicitamente como heróis da proteção do meio ambiente, capazes de transformar o sistema econômico (PASTAKIA, 1998; ISAAK, 2002; SCHALTEGGER, 2002; DIXON; CLIFFORD, 2007). Essa é a noção amplamente dominante na imprensa de negócios e perante 0 público em geral (DOUGHERTY, 1994, 2007; JONHSTON, 2006; MERRITT, 2001).

Foi apenas mais recentemente, em 2007, que os termos Sustainable Entrepreneur ou Sustainable Entrepreneurship, traduzidos como empreendedor em desenvolvimento sustentável (ED) e empreendedorismo em desenvolvimento sustentável (EDS). Ao ressaltar a ligação entre as oportunidades de negócios e a eficiência de mercado, os autores que utilizam o termo ED se posicionam desde o

${ }^{4}$ É preciso ressaltar igualmente a existência de uma literatura articulada em torno do conceito da "base da pirâmide" e que busca mostrar como o empresariado local pode favorecer o desenvolvimento nas regiões mais pobres do mundo. Como essa literatura diz mais respeito ao empreendedorismo social, ela não é abordada neste artigo (BANTOGA, 2003; HARVEY, 2006; AASERUD, 2007; PRAHALAD, 2010).

RAUFFLET, E.; BRES, L.; FILION, L. J. Desenvolvimento sustentável e empreendedorismo. Revista de Empreendedorismo e Gestão de Pequenas Empresas, v. 3, n.1, p.3-32, 2014. 
início sob uma explicação econômica. Eles se colocam num quadro schumpeteriano de criação de inovação e de criação destruidora para propor compreender a emergência deste novo tipo de empreendedor e sua relação particular com o mercado. Os autores que, nos últimos anos, começaram a falar de EDS (ALBRECHT, 2002; PASTAKIA, 1998; COHEN; WINN, 2007, DEAN; MC MULLEN, 2007) em vez de ecoempreendedor (PASTAKIA, 1998; ISAAK, 2002; SCHALTEGGER, 2002; DIXON; CLIFFORD, 2007) favorecem frequentemente uma explicação econômica para compreender a multiplicação dos EDs. Eles se baseiam em Schumpeter para afirmar que os empreendedores respondem a problemas ligados ao meio ambiente a fim de aproveitar naturalmente as deficiências do mercado. O empreendedor aparece assim como uma oscilação frente às deficiências de mercado (ver lista do Quadro 4): sob esta perspectiva, qualquer que seja o domínio de atividades, novas empresas são criadas para atender necessidades não satisfeitas e, deste modo, ocupar nichos no mercado. Desta forma, os EDs surgem porque as deficiências do mercado geram oportunidades de negócios que vão no sentido da proteção e da preservação do meio ambiente. Essa é a perspectiva no qual se situam diversos autores (DEAN; MCMULLEN, 2007; COHEN; WINN, 2007). Esta representação da conduta do empreendedor em desenvolvimento sustentável questiona as verdadeiras intenções dos empreendedores, como a vontade dos EDs de lucrar a partir dessas deficiências (KATISKIS; KYRGIDOUS, 2007). Enquanto alguns empreendedores são profundamente engajados na sobrevivência do planeta e veem a criação de uma empresa como um modo privilegiado de contribuir para o desenvolvimento sustentável, outros creem ou transformam empresas unicamente para se adequar às regras de respeito ao meio ambiente, e ainda outros veem principalmente no desenvolvimento sustentável oportunidades de negócio tais como em outros setores, sem serem verdadeiramente engajados ecologicamente.

Nesse sentido, o conceito de ED se distancia do conceito mais antigo de ecoempreendedor. No entanto, alguns dos autores que utilizam o conceito de ED pensam que as iniciativas de mercado, por elas mesmas, não explicam tudo, e que é necessário igualmente considerar as razões pessoais dos EDs (KATISKIS; KYRGIDOUS, 2007), reconciliando assim a perspectiva dos autores que falam dos 
conceitos de ecoempreendedor e de ED. As análises dos primeiros autores, mais micro centradas sob os indivíduos, poderiam assim, ser combinadas com as análises dos últimos, muito mais inscritas numa perspectiva macro econômica. Deste modo, as duas abordagens seriam complementares.

Quadro 2: Síntese: principais diferenças entre ecoempreendedor e ED

\begin{tabular}{|c|c|c|}
\hline Temática & Ecoempreendedor & $\begin{array}{l}\text { Empreendedor em } \\
\text { desenvolvimento } \\
\text { sustentável (ED) }\end{array}$ \\
\hline Disciplina de base & Ética/gestão & Economia \\
\hline Autores chave & Brundtland & Schumpeter \\
\hline Fator desencadeador & $\begin{array}{l}\text { Motivação do } \\
\text { empreendedor }\end{array}$ & Deficiência do mercado \\
\hline Perspectiva & $\begin{array}{c}\text { Micro (biografias, estudos } \\
\text { de caso, etc.) }\end{array}$ & $\begin{array}{l}\text { Macro (análise das } \\
\text { tendências sociais) }\end{array}$ \\
\hline $\begin{array}{l}\text { Natureza do } \\
\text { empreendedor }\end{array}$ & $\begin{array}{l}\text { Heroi/ideal buscado } \\
\text { (ISAAK; 2002) }\end{array}$ & $\begin{array}{l}\text { Agentes de inovação do } \\
\text { mercado }\end{array}$ \\
\hline Efeito sobre a sociedade & $\begin{array}{l}\text { Ciclo duplo (double-loop) } \\
\text { (ARGYRIS, 1993), } \\
\text { transformação do sistema }\end{array}$ & (DEAN; MCMULLEN, 2007) \\
\hline
\end{tabular}

Fonte: Elaborado pelos autores

\section{Quatro perspectivas recentes de meta-análise do campo}

Em 2007, Cohen e Winn fazem um apelo para a criação de um campo chamado Sustainable Entrepreneurship. Segundo eles, as mesmas imperfeições de mercado que, até então, geraram problemas ambientais e sociais, passaram a favorecer inovações radicais tanto de tecnologia quanto de gestão. Esse campo de empreendedorismo sustentável teria como objeto de estudo o modelo de empreendedorismo em razão do qual os atores poderiam contribuir para a resolução de problemas sociais e ambientais, em escala global e local, beneficiando-se do lucro do empreendedor, isto é, das receitas geradas entre o momento em que a inovação é difundida e o momento em que ela é imitada (COLLIS; MONTGOMERY, 
2005). Segundo Cohen e Winn (2007), dois eixos de pesquisa constituem caminhos interessantes: de um lado as relações entre as imperfeições de mercado e as oportunidades do empreendedorismo favorável ao meio ambiente, e de outro o campo emergente de EDS que resulta destas relações. Para estes dois autores, este último eixo se distingue no plano da pesquisa de campo da área de empreendedorismo pela importância dada aos objetivos sociais e ambientais, e pela vontade de exercer impacto positivo frente às questões complexas e globais do desenvolvimento sustentável (COHEN; WINN, 2007). Neste sentido, o EDS é um campo acadêmico emergente e em construção (KATSIKIS; KYRGIDOU, 2007; CHOI; GRAY, 2008).

Do ponto de vista teórico, Héron (2006) sugere que se inspire em três campos mais antigos: 1) economia neoclássica que, devido a sua abordagem centrada sob os agentes permite evidenciar estratégias vencedoras para os empreendedores em uma economia de mercado; 2) economia política que, do ponto de vista mais macro, analisa a maneira pela qual o sistema capitalista funciona na sua conjuntura; 3) economia política pós-estruturalista, mais crítica, que permite conceber um funcionamento alternativo das interações para além do sistema capitalista atual (HERON, 2006, p.124).

Para Dean e McMuller (2007), o campo emergente do EDS se situa entre as economias do bem-estar e a do campo mais clássico do empreendedorismo (Dean; McMuller, 2007). De fato, segundo estes autores, de um lado a economia do bemestar desenvolve a ideia que as deficiências de mercado estão na origem dos problemas sociais e ambientais que impedem 0 alcance dos objetivos do desenvolvimento sustentável. De outro lado, o campo do empreendedorismo vê estas mesmas deficiências como uma fonte de oportunidade de negócios. A questão para o campo de EDS consiste então, em compreender como os EDs vão explorar as deficiências para resolver os problemas sociais e ambientais, ao mesmo tempo em que geram lucros. $\mathrm{Na}$ mesma lógica, os dois autores definem 0 empreendedorismo ambiental como um subcampo do EDS, intermediário entre a economia ambiental e o empreendedorismo. 


\section{Por quê? Os fatores determinantes do EDS}

Os autores mencionam diversos fatores que favorecem o EDS: (1) a amplitude e persistência dos problemas ambientais (DEAN, 2007) representa uma forte tendência que provoca o surgimento e o desenvolvimento de atividades ligadas ao meio ambiente e a sua proteção ao longo prazo; (2) a criação de numerosas oportunidades de negócios (ROSE, 1990); (3) a importância para as empresas de apresentar uma boa imagem (CLIFTON, 2008); (4) a alta dos preços de matériasprimas que favorece o uso de energias renováveis e a economia de energia (DALE, 2008; DOHERTY, 1997; HARVEY, 2006); (5) o surgimento de novos setores de atividades econômicas: os investidores compreenderam este cenário e, nos últimos quinze anos, tem investido cada vez mais no desenvolvimento sustentável (DEAN, 2007; GANGEMI, 2008; KALHENBERG, 1992; BROAD, 1991; SEABROOK, 2004), principalmente para produzir energias renováveis (MERRITT, 2001; TODD, 2007).

Quadro 3: - Fatores determinantes que favorecem a emergência do EDS nos artigos selecionados

\begin{tabular}{|c|c|c|c|}
\hline Ano & Autor & Fatores determinantes propostos & Nível \\
\hline $\begin{array}{l}2008 \\
1997 \\
2006 \\
2007\end{array}$ & $\begin{array}{l}\text { Dale } \\
\text { Doherty } \\
\text { Harvey } \\
\text { Todd }\end{array}$ & $\begin{array}{c}\text { Aumento do preço do petróleo } \\
\text { (favorece as energias renováveis e a } \\
\text { economia de energia) }\end{array}$ & Global \\
\hline $\begin{array}{l}2007 \\
2008 \\
1992 \\
1991 \\
2004 \\
2001\end{array}$ & $\begin{array}{c}\text { Dean } \\
\text { Gangemi } \\
\text { Kalhenberg } \\
\text { Broad } \\
\text { Seabrook } \\
\text { Meritt }\end{array}$ & $\begin{array}{l}\text { Fundos de investimentos dedicados } \\
\text { ao meio ambiente }\end{array}$ & Global \\
\hline 2007 & Dean & Problemas ambientais & Global \\
\hline 1990 & Rose & $\begin{array}{l}\text { Crise ambiental como fonte de } \\
\text { oportunidades de negócios }\end{array}$ & Global \\
\hline $\begin{array}{l}2006 \\
2007\end{array}$ & $\begin{array}{l}\text { Bonnet et al. } \\
\text { Tracey; Philipps }\end{array}$ & Promoção da educação ambiental & Nacional \\
\hline 2002 & Isaak & $\begin{array}{l}\text { Compromisso do poder público } \\
\text { (iniciativas fiscais, campanhas de } \\
\text { formação de opinião) }\end{array}$ & Nacional \\
\hline 2008 & Clifton & Boa imagem & Empresarial \\
\hline 2005 & Schaper & Benefícios de imagem & Empresarial \\
\hline 1997 & Hendrickson; Tuttle & $\begin{array}{c}\text { Tipologia: os valores, o mercado e a } \\
\text { conformidade }\end{array}$ & \\
\hline
\end{tabular}

Fonte: Elaborado pelos autores

RAUFFLET, E.; BRES, L.; FILION, L. J. Desenvolvimento sustentável e empreendedorismo. Revista de Empreendedorismo e Gestão de Pequenas Empresas, v. 3, n.1, p.3-32, 2014. 
De forma mais sintética, Hendrickson e Tutlle (1997) propõe agrupar os fatores determinantes do EDS sob três categorias: os valores, o mercado e a conformidade. Os valores compreendem a ética pessoal do empreendedor em função da qual ele vai buscar desenvolver uma empresa de acordo com os objetivos do desenvolvimento sustentável; o mercado se refere às oportunidades de negócios ligadas ao desenvolvimento sustentável; e a conformidade remete às pressões normativas exigidas aos empreendedores para se adequar às regras de comportamento em função do que é socialmente aceitável.

\section{Quem?}

Duas abordagens principais buscam compreender e caracterizar os EDs: os estudos de casos individuais e as tipologias/taxonomias, conforme apresentado a seguir.

Intracaso: os estudos de casos individuais apresentam geralmente os EDs como personagens complexos e fascinantes. Alguns autores observam que eles demonstram possuir padrões éticos bastante elevados ( $\mathrm{CHOI}$; GRAY, 2008). Mas, na maioria dos textos as suas motivações oscilam entre 0 idealismo e 0 pragmatismo (WALLEY; TAYLOR, 2002; LINNANEN, 2002; SCHAPER, 2005). Duas tendências não necessariamente incompatíveis cuja reconciliação permite a criação de empresas do tipo "ganha-ganha", isto é, que geram lucros ao mesmo tempo em que favorecem o bem-estar social e respeitam o meio ambiente (CATHY; EDWYN, 1998). Quaisquer que sejam as suas motivações reais, estes empreendedores beneficiam-se frequentemente do status de heróis, graças aos valores que eles promovem em suas ações à sociedade (SCHAPER, 2005). Por esta razão, multiplicam-se as biografias de grandes EDs (BRADY, 2004; BROAD, 1991; DOUGHERTY, 1994; DOUGHERTY, 2007; WADDOCK, 2008).

Intercasos: as taxonomias. As pesquisas taxonômicas se estruturam frequentemente em torno da tensão entre idealismo e oportunismo e sugerem identificar diferentes tipos de EDs (LINNANEN, 2002; SCHAPER, 2005; WALLEY; TAYLOR, 2002). Notadamente, para os pesquisadores que, desde 2007, buscam a formação do EDS, os EDs exploram antes de tudo as deficiências de mercado e 
contribuem para reduzi-las. Neste sentido, Dean e McMullen (2007) propõem uma tipologia de empreendedores em função da deficiência de mercado que eles buscam explorar. Por fim, pode-se notar uma tipologia original: Gerlach (2006) sugere que se pense o EDS de maneira processual, em ligação com a política e a criação de regras sobre o desenvolvimento sustentável. Ele distingue os promotores do desenvolvimento sustentável dentro das organizações em função de seus diferentes domínios de expertise. Esse domínio de expertise define o momento onde eles intervêm no processo de criação e de concretização de regras sobre o desenvolvimento sustentável. Em cada etapa deste processo um tipo particular de ED intervém de maneira privilegiada (GERLACH, 2006). O Quadro 4 apresenta as diferentes tipologias.

Quadro 4: - Fatores determinantes que favorecem a emergência do EDS nos artigos selecionados

\begin{tabular}{|c|c|c|c|c|}
\hline Ano & Autores & Critérios da tipologia & $\begin{array}{c}\text { Tipos de } \\
\text { empreendedores }\end{array}$ & $\begin{array}{c}\text { Exemplos } \\
\text { mencionados }\end{array}$ \\
\hline \multirow[t]{4}{*}{2002} & \multirow[t]{4}{*}{$\begin{array}{l}\text { Walley; } \\
\text { Taylor }\end{array}$} & \multirow{4}{*}{$\begin{array}{l}\text { - Orientação para o } \\
\text { desenvolvimento } \\
\text { sustentável ou } \\
\text { orientação } \\
\text { econômica } \\
\text { - Ambiente socio- } \\
\text { político favorável ou } \\
\text { desfavorável ao } \\
\text { desenvolvimento } \\
\text { sustentável }\end{array}$} & Oportunista inovador & $\begin{array}{l}\text { Evan Connell (The } \\
\text { Connell Group }{ }^{5} \text { ) }\end{array}$ \\
\hline & & & Campeão visionário & $\begin{array}{l}\text { Anita Roddick (The } \\
\text { Body Shop }{ }^{6} \text { ) }\end{array}$ \\
\hline & & & Maverick ético & $\begin{array}{l}\text { Founder of The } 8^{\text {th }} \\
\text { Day' Vegetarian } \\
\text { Cafe }^{7} \text { (Manchester) }\end{array}$ \\
\hline & & & $\begin{array}{l}\text { Empreendedor } \\
\text { ambiental adhoc }\end{array}$ & $\begin{array}{l}\text { Tom Archer (The } \\
\text { Archers }^{8} \text { ) }\end{array}$ \\
\hline \multirow[t]{4}{*}{2002} & \multirow[t]{4}{*}{ Linnanen } & \multirow{4}{*}{$\begin{array}{l}\text { Continuum entre a } \\
\text { vontade de fazer } \\
\text { lucros e o idealismo }\end{array}$} & $\begin{array}{l}\begin{array}{l}\text { Negócios sem fins } \\
\text { lucrativos }\end{array} \\
\end{array}$ & Sem exemplo \\
\hline & & & Idealista bem-sucedido & Sem exemplo \\
\hline & & & Oportunista & Sem exemplo \\
\hline & & & Autoempregado & Sem exemplo \\
\hline 2002 & Shaltegger & - Impacto do & $\begin{array}{l}\text { Administração } \\
\text { ambiental }\end{array}$ & $\begin{array}{l}\text { Sistemas: } \text { ISO }^{9} \\
\text { 14000, } \text { EMAS }^{10}\end{array}$ \\
\hline
\end{tabular}

Sites consultados em Junho/2011:

${ }^{5} \mathrm{http}: / /$ www.theconnellgroup.co.uk/

6 http://www.thebodyshop.ca/en/index.aspx

7 http://www.eighth-day.co.uk/

8 http://www.bbc.co.uk/radio4/features/the-archers/

9 http://www.iso.org/iso/home.html

${ }^{10}$ http://ec.europa.eu/environment/emas/index en.htm

RAUFFLET, E.; BRES, L.; FILION, L. J. Desenvolvimento sustentável e empreendedorismo. Revista de Empreendedorismo e Gestão de Pequenas Empresas, v. 3, n.1, p.3-32, 2014. 


\begin{tabular}{|c|c|c|c|c|}
\hline & & \multirow{4}{*}{$\begin{array}{l}\text { empreendedor } \\
\text { sobre o seu setor } \\
\text { industrial } \\
\text { - Prioridade das } \\
\text { questões ambientais } \\
\text { (ecoempreendedor } \\
\text { visto como o última } \\
\text { etapa do } \\
\text { desenvolvimento de } \\
\text { EDS) }\end{array}$} & Gestão ambiental & \multirow{2}{*}{\begin{tabular}{|l} 
Geberit Ltd. ${ }^{11}$ \\
Ballard Power
\end{tabular}} \\
\hline & & & Atores alternativos & \\
\hline & & & $\begin{array}{l}\text { Bioneer } \\
\text { biológico » }\end{array}$ & Hess Nature ${ }^{13}$ \\
\hline & & & Ecoempreendedor & Landis $\&$ Staefa $^{14}$ \\
\hline \multirow[t]{4}{*}{2006} & \multirow[t]{4}{*}{ Gehrlach } & \multirow{4}{*}{$\begin{array}{l}\text { Domínio de } \\
\text { expertise (expertise } \\
\text { política, capacidade } \\
\text { de inovar, gestão, } \\
\text { rede) }\end{array}$} & Promotor de poder & $\begin{array}{l}\text { BP Group }{ }^{15} \text { CEO Sir } \\
\text { John Browne }\end{array}$ \\
\hline & & & Promotor de expertise & Comissão específica \\
\hline & & & Promotor de processo & Sem exemplo \\
\hline & & & $\begin{array}{ll}\begin{array}{l}\text { Promotor } \\
\text { relacionamento }\end{array} & \mathrm{de} \\
\end{array}$ & Sem exemplo \\
\hline \multirow[t]{5}{*}{2007} & \multirow[t]{5}{*}{$\begin{array}{l}\text { Dean } \\
\text { McMullen }\end{array}$} & \multirow{5}{*}{$\begin{array}{l}\text { - Um tipo de } \\
\text { empreendedor para } \\
\text { cada tipo de } \\
\text { deficiência de } \\
\text { mercado }\end{array}$} & $\begin{array}{l}\text { Empreendedorismo } \\
\text { Coasiano (bem público) }\end{array}$ & $\begin{array}{l}\text { Mantenedores de } \\
\text { faróis privados }\end{array}$ \\
\hline & & & $\begin{array}{l}\text { Empreendedorismo } \\
\text { institucional } \\
\text { (externalidades) }\end{array}$ & $\begin{array}{l}\text { Richard Sandor } \\
(\text { Chicago Climate } \\
\left.\text { Exchange }^{16}\right)\end{array}$ \\
\hline & & & $\begin{array}{l}\text { Empreendedorismo de } \\
\text { apropriação de mercado } \\
\text { (poder monopolítico) }\end{array}$ & $\mathrm{MCI}$ telecom ${ }^{17}$ \\
\hline & & & $\begin{array}{l}\text { Empreendedorismo } \\
\text { político } \\
\text { (intervenção } \\
\text { governamental } \\
\text { produtiva) }\end{array}$ & $\begin{array}{l}\text { Privatização da } \\
\text { indústria } \\
\text { de selos dos EUA }\end{array}$ \\
\hline & & & $\begin{array}{l}\text { Empreendedor } \\
\text { informacional } \\
\text { (informação imperfeita) }\end{array}$ & Clipper Wind $^{18}$ \\
\hline
\end{tabular}

Fonte: Elaborado pelos autores

${ }^{11}$ http://www.geberit.co.uk/web/appl/uk/wcmsuk.nsf/pages/index

${ }^{12}$ http://www.ballard.com/

${ }^{13} \mathrm{http} / / /$ de.hessnatur.com/shop/showCmsContent.action?contentID=home

${ }^{14} \mathrm{http}: / /$ www.landisandstaefa.co.za/

15 http://www.bpgroup.ca/

16 http://www.chicagoclimatex.com/

${ }_{17} \mathrm{http://www.mci.com/}$

${ }^{18}$ http://www.clipperwind.com/ 


\section{Compreendendo as características comuns}

A fim de buscar evidenciar as características comuns a todos os EDs, Choi e Gray (2008) compararam 21 EDs - cabe destacar que, em relação às questões de empreendedorismo e desenvolvimento sustentável, que são geralmente abordadas baseando-se em alguns estudos de casos, trata-se de uma amostragem incomumente elevada. De acordo com as suas conclusões, três pontos são salientados: 1) estes empreendedores geralmente não possuem grandes conhecimentos em gestão; 2) eles têm a capacidade de obter financiamentos não convencionais, favorecendo notadamente mais os empréstimos de pessoas próximas do que de investidores tradicionais, a fim de conservar sua margem de manobra; 3) eles possuem uma gestão coerente e eficaz de seus colaboradores, ainda que pouco ortodoxa (CHOI; CRAY, 2008).

\section{Como? Processo de inovação em gestão}

A inovação constitui o coração do empreendedorismo "clássico". No EDS os desafios da inovação aumentam de maneira exponencial. Desde o lançamento, uma ambição ambiental muito forte pode tornar um produto inadequado ao seu mercado. Existe então um processo de desenvolvimento de produtos específico ao EDS, ao longo do qual é preciso considerar as necessidades do mercado, isto é, ser capaz de encontrar um equilíbrio entre a ambição ambiental e a lucratividade, a fim de permitir que a empresa continue em atividade (BERCHICCI, 2005). Além disso, e em um plano talvez mais fundamental, quando se faz referência à inovação de ordem tecnológica, alguns autores colocam em questão a capacidade da ciência e das tecnologias de realmente enfrentar os problemas ambientais (JONAS, 1990).

No empreendedorismo sustentável, é a própria natureza da tecnologia que é questionada, e é preciso repensar a maneira de abordar a inovação (WENNERSTEN, 2008; MCDONOUGH; BRAUNGART, 2002). Uma resposta interessante que tem sido data pelos EDs consiste em tomar a natureza a fonte e modelo de inovações, como o biomimetismo, por exemplo, que consiste em conceber produtos cujo design e funcionamento imitam os processos observados na 
natureza (LARSON, 2000; BENYUS, 1997). Em suma, para os EDs o processo de inovação é muito mais complexo do que para os empreendedores clássicos, em função da multiplicidade de objetivos perseguidos.

\section{Os processos de gestão}

Ainda há muito a ser desenvolvido nos estudos dos processos de gestão específicos dos EDs. De fato, como já salientou Schaper (2002), o estudo deste fenômeno tem sido feito principalmente de maneira pontual, caso por caso. Entretanto, depois de alguns anos, já é possível encontrar um comércio destinado ao público em geral com um certo número de obras propondo conselhos para se lançar no empreendedorismo do desenvolvimento sustentável (BENNETT, 1991; POLLARD, 2008; MARTINEZ, 2008).

Recentemente, no estudo anteriormente mencionado de 21 empreendedores que tiveram sucesso no desenvolvimento sustentável, Choi e Gray (2008) destacaram a importância dos valores na gestão. Eles afirmam que os valores que esses empreendedores promovem tem impacto sobre pelo menos três principais pontos: os financiamentos, a gestão dos colaboradores e a medida de performance (CHOI; GRAY, 2008). Pouco depois, ao longo do ano 2000, eles ampliaram o seu estudo para trinta empreendedores bem sucedidos no desenvolvimento sustentável e propuseram recomendações para os empreendedores que desejam se lançar nesse caminho (ver Anexo A). Outra recomendação pode ser inferida do estudo realizado por Borges, Filion e Simard (2013) que indica que a rapidez das atividades do processo de criação não garante um melhor desempenho ao negócio. Assim, os autores recomendam aos empreendedores e às pessoas que trabalham no apoio ao empreendedorismo, uma excelente preparação, em outras palavras, a criação da empresa não pode ser negligenciada em razão do tempo que tal preparação pode requerer, principalmente quando se trata de um novo campo, como o EDS. 


\section{Onde? Os atuais setores do EDS e a emergência de novos setores}

Novas oportunidades de negócios ligadas ao desenvolvimento sustentável vêm surgindo em setores clássicos da indústria, como a indústria alimentícia (Nation's Restaurant News, 1995; MARDSEN; SMITH, 2005) no setor de entretenimento (WARNOCK, 2008), indústria farmacêutica e os setores da saúde (JEKWA, 2008). Notam-se também novos setores de atividades como o ecoturismo (JONES, 1999; LORDKIPANIDZE, BREZET; BACKMAN, 2005) e energias renováveis (CLARK, 2004; DALE, 2008; DOHERTY, 1997; HARVEY, 2006; JOHNSTON, 2006; MERRITT, 2001). As atividades ligadas às energias renováveis tiveram um verdadeiro boom depois das elevações cíclicas e frequentes do preço do petróleo ao longo da última década (DALE, 2008; HARVEY, 2006). Quinn (1971) foi provavelmente o primeiro a prever a explosão destas atividades. Tem-se presenciado também a emergência de setores de atividade especificamente ligados à proteção do meio ambiente e ao desenvolvimento sustentável. Particularmente, para os analistas, cinco novos setores emergiram desde o começo dos anos 1990 (FISCHETTI; JAREAUX, 1992): (1) indústria da reciclagem (DOUGHERTY, 1994; OJEDA-BENITEZ; ARMIJO-DE-VEJA; RAMÍREZ-BARRETO, 2002); (2) limpeza de zonas poluídas; (3) controle da poluição atmosférica e a captação de gases, que teve um forte crescimento com o estabelecimento das bolsas de carbono (DOUGHERTY, 2007; KAMARUDDIN; SAYRIGH, 2000); (4) tratamento da água; (5) engenharia e os serviços de consultoria. Globalmente, estima-se que o mercado de bens e serviços ambientais represente anualmente 1370 bilhões de dólares e duplicará até 2020; igualmente espera-se a criação de mais de vinte milhões de novos empregos (UNEP, 2006). 


\section{Quadro 5: Setores emergentes e EDS}

\begin{tabular}{|c|c|c|}
\hline \multirow[t]{3}{*}{$\begin{array}{l}\text { Novas oportunidades em } \\
\text { antigos setores }\end{array}$} & Indústria alimentícia & $\begin{array}{l}\text { Nation's Restaurant News, } \\
1999 \\
\text { Mardsen; Smith, } 2005\end{array}$ \\
\hline & $\begin{array}{ll}\text { Indústria } & \text { do } \\
\text { entretenimento } & \end{array}$ & Warnock, 2008 \\
\hline & Indústria farmacêutica & Jekwa, 2008 \\
\hline \multirow[t]{2}{*}{$\begin{array}{l}\text { Novas atividades em } \\
\text { setores antigos }\end{array}$} & Ecoturismo & $\begin{array}{l}\text { Jones, } 1999 \\
\text { Lordkipanidze; } \quad \text { Brezet; } \\
\text { Backman, 2005 }\end{array}$ \\
\hline & Energias renováveis & 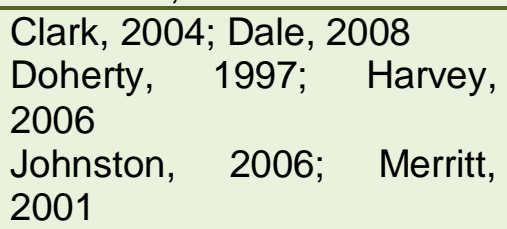 \\
\hline \multirow[t]{5}{*}{$\begin{array}{l}\text { Novos setores de } \\
\text { atividades } \\
\text { (Fischetti; Jareaux, 1992) }\end{array}$} & Indústria da reciclagem & $\begin{array}{l}\text { Dougherty, 1994; } \\
\text { Ojeda-Benitez; Armijo-de- } \\
\text { Vega; Ramírez-Barreto, } \\
2002\end{array}$ \\
\hline & $\begin{array}{l}\text { Limpeza das zonas } \\
\text { poluídas }\end{array}$ & \\
\hline & $\begin{array}{l}\text { Controle da poluição } \\
\text { atmosférica }\end{array}$ & $\begin{array}{l}\text { Dougherty, } 2007 \\
\text { Kamaruddin; Sayrigh, } 2000\end{array}$ \\
\hline & Tratamento da água & \\
\hline & $\begin{array}{l}\text { Engenharia e serviços de } \\
\text { consultoria }\end{array}$ & \\
\hline
\end{tabular}

Fonte: Elaborado pelos autores

Linnanen (2002) propõe uma outra tipologia de quatro eco-setores, isto é, setores industriais ligados à luta contra a poluição, a partir de fatores determinantes que influenciam a sua emergência. Três tipos de fatores intervêm no surgimento de eco-setores: 1) escala (local, regional e global); 2) fatores de poluição; 3) natureza das oportunidades de negócios, ou seja, se elas são frutos de iniciativas voluntárias (o mercado) ou das leis. No caso das leis ou regulamentações cabe também distinguir em que medida elas são compulsórias ou não. 
Quadro 6: Os determinantes da emergência dos eco-setores

\begin{tabular}{|l|c|c|c|}
\hline \multirow{2}{*}{ Segmento } & \multicolumn{3}{|c|}{ Driver } \\
\cline { 2 - 4 } & $\begin{array}{c}\text { Influência } \\
\text { geográfica }\end{array}$ & $\begin{array}{c}\text { Razões para } \\
\text { emergência de } \\
\text { mercado }\end{array}$ & Grau de aplicação \\
\hline $\begin{array}{l}\text { Empresas orientadas } \\
\text { pela natureza }\end{array}$ & Local & Mercado & Baixo \\
\hline Tecnologia ambiental & Local ou regional & Regulação & Alto \\
\hline $\begin{array}{l}\text { Serviços de gestão } \\
\text { ambiental }\end{array}$ & Global & Regulação e mercado & Baixo \\
\hline Produtos ambientais & Global & Mercado & Baixo \\
\hline
\end{tabular}

Fonte: Linnanen (2002)

\section{Emergência de novas culturas e novos contextos de negócios para os setores de atividades emergentes}

A multiplicação de oportunidades de negócios ligadas ao desenvolvimento sustentável deu origem a novos tipos de empresas e novas culturas empreendedoras. O seu surgimento tem sido facilitado por contextos e estruturas de negócios originais favorecendo o EDS e vem se constituindo gradativamente. Podem ser mencionadas empresas como a Sustaintech que coloca em contato EDs e investidores (BUSINESS, 2004); o guia Chic Eco que relaciona os empreendedores que propõem produtos e serviços ecológicos e chiques (THE CENTER, 1995; GLASKIN, 2004; Colloque du OCRE-EDC, 2007); e a Cataléthique em Montreal, uma atividade desenvolvida a partir da maioria dos colóquios universitários em empreendedorismo/PME, que diz respeito ao desenvolvimento sustentável e ao empreendedorismo e às veiculações nas mídias dedicadas ao meio ambiente e ao desenvolvimento sustentável (GARMHAUSEN; JOHNSON; DELANEY, 2008).

A fim de especificar as atividades empreendedoras propriamente ligadas ao desenvolvimento sustentável, Schaltegger (2002) propõe retomar o conceito de Issak (2002) para estabelecer uma tipologia em função da integração de atividades ambientais no core business das empresas, e de sua capacidade de impactar o mercado. O ecoempreendedorismo torna-se, então, a propriedade de empresas cujo 
core business está ligado à melhoria do meio ambiente e, sobretudo, cujos produtos e serviços se destinam ao consumo de massa (SCHALTEGGER, 2002)

Obviamente, o empreendedorismo social e, em particular, o empreendedorismo ecológico, devem enfrentar um certo número de desafios, entre os quais: (1) resistências políticas, (2) falta de conhecimentos ou de know-how dos experts sobre as questões do desenvolvimento sustentável (GERLACH, 2006), (3) certa dificuldade de manter a confiança do público (IRITANI, 2007; SCHAPER, 2005). Cabe ainda mencionar a relativa indiferença da maioria dos consumidores, bastante sensíveis ao preço, mas sem considerar realmente os efeitos nocivos do seu consumo sobre o meio ambiente.

Apesar disso, é verdade que a ação dos poderes públicos é crítica, Isaak (2002) identifica três meios para que os poderes públicos favoreçam o EDS: (1) estabelecer incentivos fiscais que favoreçam a criação de empregos verdes e sancionem o uso dos recursos; (2) utilizar o ecoempreendedorismo para favorecer o civismo; (3) conduzir campanhas públicas para deslegitimizar empresas que não são sustentáveis (ISAAK, 2002).

\section{Conclusões e caminhos para pesquisas futuras}

Unir empreendedorismo, frequentemente pensado como uma iniciativa individualista, materialista, oportunista e motivada pelo ganho (POTOCAN; MULEJ, 2003; SURIE; ASCHLEY, 2008; ANDERSON, 1998), e menos frequentemente numa perspectiva centrada na criação de riqueza coletiva (YOUNG; TILLEY, 2006), e desenvolvimento sustentável, assunto essencialmente associado a aspectos sociais e ambientais, coletivos e orientados para o longo prazo, pode parecer paradoxal a priori. No entanto, o significativo desenvolvimento de atividades e pesquisas em empreendedorismo social, desde o início dos anos 1990, tem mostrado que esse paradoxo produz bons resultados em termos de pesquisa.

Neste sentido, verifica-se que na prática existe uma proporção não negligenciável de empreendedores que criam empresas numa perspectiva de contribuição social (FILION, 2002; FILION; LUC; FORTIN, 2003). Alguns pesquisadores demonstraram que esta tendência se acentua e identificaram que 
$10 \%$ das empresas criadas nas regiões mais afastadas do Quebec, no início dos anos 2000, foram criadas em função de objetivos de contribuição ao desenvolvimento da localidade (BORGES; SIMARD; FILION, 2005).

O desenvolvimento sustentável constitui uma causa nobre e as pessoas que nele se engajam têm necessidade de meios que permitam trabalhar nesta causa, e continuar este trabalho no longo prazo. O empreendedorismo pode fornecer ao desenvolvimento sustentável este meio e até mesmo o pontapé inicial necessário para que ele realmente alce seu voo. Ao longo dos últimos anos diversas pontas foram construídas entre esses dois campos, a fim de iniciar novas práticas repletas de promessas para melhor proteger o meio ambiente, ajudar a deter a poluição e a destruição massiva que vem se acentuando ao longo dos últimos séculos.

Diversas iniciativas e empresas com fins não lucrativos, em uma perspectiva de proteção da natureza, podem abrir caminhos de pesquisa para o empreendedorismo ecológico. Isto é o que vem tentando demonstrar certos autores que exploraram experiências de expressão empreendedora ligadas à conservação e à valorização dos espaços naturais (RAUFFLET et al., 2010).

Esta reflexão crítica sobre os trabalhos em EDS busca identificar caminhos estruturantes de pesquisa que possam servir para melhor integrar esses dois campos. É certo que, apesar de alguns primeiros passos, o campo de EDS tem muito a ser desenvolvido. Alguns direcionamentos são sugeridos a seguir.

\section{O quê?}

Mesmo que ainda não seja o momento para integração dos conhecimentos, pode ser interessante a busca de reconciliação entre a perspectiva dos autores que falam do ecoempreendedorismo com a dos autores que falam de EDS. As perspectivas dos promotores do ecoempreendedorismo e as perspectivas do EDS poderiam ser objeto de uma comparação aprofundada para melhor destacar as diferenças, e também os pontos convergentes entre as duas abordagens. Essas duas perspectivas são somente complementares e destinadas a se desenvolver em paralelo ou elas podem ser integradas? É provável que existam muitos efeitos sinérgicos potenciais resultantes de seu desenvolvimento integrado. Do ponto de 
vista epistemológico, seria necessário examinar a própria estruturação do EDS, para saber se esse campo em emergência não teria mais benefícios estruturando-se a partir de duas perspectivas que refletem cada uma das diferentes práticas mais frequentemente encontradas: 1) a dos ecoempreendedores, 2) a dos empreendedores que veem no desenvolvimento sustentável oportunidades como em qualquer outro tipo de negócio.

\section{Quem: além dos estudos de caso}

As abordagens metodológicas utilizadas compreendem essencialmente os estudos de alguns casos discutindo (1) atenção entre o idealismo e o pragmatismo dos empreendedores e (2) a construção de tipologias. Foi apenas recentemente que pesquisadores e órgãos de pesquisa começaram a trabalhar sobre amostragens mais amplas. Wagner e Schaltegger (2010), por exemplo, sustentam a sua tipologia sobre a análise de mais de 40 empresas europeias. Em 2010, a fundação de empreendedorismo do Quebec produziu um estudo conjunto com a empresa de sondagem Léger Marketing e a Caixa de Previdência (Caisse de dépôt) do governo do Quebec sobre a questão do EDS, com a participação de mais de 7300 quebequenses. Neste estudo, os empreendedores com menos de 35 anos de idade aparecem como particularmente sensíveis a esta questão.

Além disso, propõem-se aqui diversos outros caminhos de pesquisa ao redor dos próprios empreendedores. Quais são as particularidades dos sistemas de pensamento e das atividades próprias aos empreendedores engajados no desenvolvimento sustentável (FILION, 1999; FILION; BOURION, 2008)? Qual é a relação entre os valores sociais e a prática empreendedora dos atores engajados em atividades de desenvolvimento sustentável? Quais são as particularidades dos sistemas relacionais dos empreendedores engajados em atividades de desenvolvimento sustentável? Quais são as características da sua organização e dos recursos que eles possuem? Quais são as especificidades associadas a sua forma de identificar, desenvolver e gerar oportunidade empreendedora, a partir da qual eles vão conceber o seu sistema empreendedor? Pode ser interessante observar suas atividades no cotidiano (MINTZBERG, 1973; HILL, 1991). Quais são 
as características comuns aos EDs? Qual é o passado e o futuro dos empreendedores engajados em atividades de desenvolvimento sustentável, assim como as possíveis mudanças para aqueles que abandonam estas atividades?

\section{Como? criar e dividir a riqueza}

Outro caminho poderia discutir sobre as particularidades dos processos de inovação e gestão do empreendedorismo no contexto do desenvolvimento sustentável, as dificuldades encontradas no momento do início de um novo negócio, e assim por diante. Os modelos de negócios de desenvolvimento sustentável têm sido pouco estudados na literatura (um único autor nos artigos selecionados neste estudo). Assim, as formas e estilos de gestão específicos ao EDS ainda podem ser mais explorados. Em que medida estes processos de gestão e inovação são diferentes ou parecidos com os processos clássicos de empreendedorismo? Quais são as formas, modalidades e momentos de inserção de preocupações ambientais e/ou sociais no processo de criação de riqueza, que é o processo empreendedor? Quais são as diferenças nas formas de distribuição da riqueza entre o empreendedorismo clássico e o EDS? E, com base em Borges e Filion (2012): qual o capital social envolvido neste tipo de negócio? Qual o papel das Universidades e suas incubadoras neste processo?

Boa parte das pesquisas tem discutido acerca dos indivíduos numa perspectiva diacrônica (em um momento $t$ ). O ED é apresentado como indivíduo capaz de reconciliar lógicas de negócios, bem-estar social e preservação ou melhoria do meio ambiente. Entretanto, como, no ciclo de vida e de negócios da empresa em crescimento, o empreendedor é capaz de reconciliar esse modelo de negócios que resulta de um círculo virtuoso de crescimento com os setores mais comerciais que, por sua vez, não são sempre caracterizados por suas preocupações sociais e ambientais? Um caminho de pesquisa poderia examinar os dilemas do mainstreaming de suas iniciativas em matéria de desenvolvimento sustentável. 


\section{Para onde?}

Por fim, nenhum estudo buscou considerar o impacto real dos EDs, à exceção dos efeitos isolados de alguns casos particulares. É sabido que algumas dessas iniciativas resultaram em efeito ou aprendizagem de "ciclo único" (do inglês single loop) - compensando as deficiências de mercado - e outras tiveram aprendizagem ou efeito de "ciclo duplo" (do inglês double loop) - transformando o mercado, a partir de impactos e mudanças mais radicais. Entretanto, até que ponto esses empreendedores são capazes de contribuir individualmente para uma transformação do sistema de consumo em direção a uma redução do consumo ou em direção a um consumo mais ecológico?

\section{Referências:}

AASERUD, K. A new kind of debt relief. Profit Magazin, v. 26, n. 3, p. 11-13, 2007.

ACTOR, Blythe Danner, Energy Vision President Joanna Underwood, NYC Environmental, Community \& Energy Activists, Elected Officials and "Green" Entrepreneurs Unveil New Natural Gas Garbage Trucks at Union Square Event. Business Wire, 2008.

ALBRECHT, J. Environmental issue entrepreneurship: A Schumpeterian perspective. Futures, v. 34, n. 7, p. 649-661, 2002.

ANDERSON, A. R. Cultivating the Garden of Eden: Environmental entrepreneuring. Journal of Organizational Change Management, v. 11, n. 2, p. 135-144, 1998.

ARGYRIS, C. Knowledge for action: a guide to overcoming barriers to organizational change. 1. ed. San Francisco: Jossey-Bass, 1993.

BENYUS, J. M. Biomimicry: Innovation inspired by nature. 1. ed. New York: William Morrow, 1997.

BERCHICCI, L. The green entrepreneur's challenge: The influence of environmental ambition in new product development. 2005. 261f. Tese Faculdade de Design, Engenharia e Produção, Technische Universiteit Delft, Holanda, 2005.

BONNET, H.; QUIST, J.; HOOGWATER, D.; SPAANS, J.; WEHRMANN, C. Teaching sustainable entrepreneurship to engineering students: The case of Delft 
University of Technology. European Journal of Engineering Education, v. 31, n. 2, p. 155-167, 2006.

BORGES, C.; SIMARD, G.; FILION, L.J. Entreprendre au Québec, c'est capital! Résultats de recherches sur la création d'entreprises. Cahier de recherche 2005-03, Chaire d'entrepreneuriat Rogers-J.-A.-Bombardier, HEC Montréal, 2005.

; FILION, L.J.; SIMARD, G. Criação de empresas: um processo mais rápido e fácil resulta em empresas de melhor desempenho? Revista de Ciências da Administração, v. 15, n. 35, p. 196-207, 2013.

; FILION, L.J. Evolução do capital social empreendedor dos spin-offs universitários. Revista de Empreendedorismo e Gestão de Pequenas Empresas REGEPE, v. 1, n. 1, p. 3-31, 2012.

BRADY, D. Household Name? Not Yet. Business Week, n. 3910, p. 106, 2004.

BRES, L.; RAUFFLET, E.; FILION, L.J. Développement durable et entrepreneuriat. In: COLLOQUE DE L'ASSOCIATION DES SCIENCES ADMINISTRATIVES DU CANADA/ADMINISTRATIVE SCIENCES ASSOCIATION OF CANADA (ASAC), 2011, Université du Québec à Montréal (UQAM). Anais... HEC Montreal: Cahier de recherche 2011-05, Chaire d'entrepreneuriat Rogers-J.-A.-Bombardier, 2011, n. p.

BROAD, W. J. As Biosphere Is Sealed, Its Patron Reflects on Life. New York Times: C1, 1991.

BUSINESS matchmaker aims at high-risk green sector, The Courier-Mail, v. 32, 2004

CATHY, L. H.; EDWIN, R. S. Crafting "enviropreneurial" value chain strategies through green alliances. Business Horizons, v. 41, n. 2, p. 62-73, 1998.

CHOI, D. Y.; GRAY, E. R. The venture development processes of "sustainable" entrepreneurs. Management Research News, v. 31, n. 8, p. 558-569, 2008.

CLARK, Linda. Sustainability conference Mobilizes Ecopreneurs. In Business, v. 26, n 4, p. 4-5, 2004.

CLIFTON, R. In my opinion. Management Today, v. 12, 2008.

COHEN, B.; WINN, M. I. Market imperfections, opportunity and sustainable entrepreneurship. Journal of Business Venturing, v. 22, n. 1, p. 29-49, 2007.

COLLIS, D. J.; MONTGOMERY, C. A. Corporate strategy: a resource-based approach. 2. ed. Boston, Mass.: McGraw-Hill/Irwin, 2005.

RAUFFLET, E.; BRES, L.; FILION, L. J. Desenvolvimento sustentável e empreendedorismo. Revista de Empreendedorismo e Gestão de Pequenas Empresas, v. 3, n.1, p.3-32, 2014. 
DALE, A. Green Products Gain From New Price Equation: They Find New Buyers As High Energy Costs Hurt Regular Brands. Wall Street Journal - Eastern Edition, v. 251, n. 147, 2008. Disponível em:

$<$ http://online.wsj.com/news/articles/SB121425785415998071>. Acesso: 25 jun 2008.

DEAN, T. J.; MCMULLEN, J. S. Toward a theory of sustainable entrepreneurship: Reducing environmental degradation through entrepreneurial action. Journal of Business Venturing, v. 22, n. 1, p. 50-76, 2007.

DEAN, V. Painting the Town Green. ABA Bankers News, v. 15, n. 12, p. 7, 2007.

DIXON, S. E. A.; CLIFFORD, A. Ecopreneurship - A new approach to managing the triple bottom line. Journal of Organizational Change Management, v. 20, n. 3, p. 326-345, 2007.

DOHERTY, A. Finding the right places for renewable energy. In Business, v. 19, n. 3, p. 25, 1997.

DOUGHERTY, S. Helping cool off our planet; Green entrepreneurs Cansolv's profit starts to sprout after five years of work developing scrubbing technologies to capture industrial gas emissions. Now, the firm's techniques could play a key role in fighting global warming, The Gazette: B.2, 2007.

DOUGHERTY, T. A. Green entrepreneurs: Recycling has created a glut of recycled materials, but these companies have found unique uses and created new products. Marketplace Magazine, v. 5, n. 4, p. 14, 1994.

FILION, L.J. Empirical Systems Modeling Methodology (ESM): Applications to Entrepreneurial Actors. In: WAGNER, J.A. III (Ed.). Advances in Qualitative Organization Research, Stamford, CT: Jai Press, v. 2, p. 201-220, 1999.

Montréal, 2002.

Savoir entreprendre. Montréal, Qc: Presses de l'Université de

; BOURION, C. Les représentations entrepreneuriales. Paris: Éditions ESKA, 2008.

; LIMA, E. As Representações Empreendedoras: Importantes Temas para Avançar em seu Estudo. RN - Revista de Negócios, v. 15, n. 2, p. 32-52, 2010.

; LUC, D.; FORTIN, P.A. L'essaimage d'entreprises. Vers de nouvelles pratiques entrepreneuriales. Montréal, Qc: Éditions Transcontinental, 2003.

FISCHETTI, M.; JAREAUX, R. Green entrepreneurs. Technology Review, v. 95, n. 3, p. 38-45, 1992.

RAUFFLET, E.; BRES, L.; FILION, L. J. Desenvolvimento sustentável e empreendedorismo. Revista de Empreendedorismo e Gestão de Pequenas Empresas, v. 3, n.1, p.3-32, 2014. 
GANGEMI, J. Green Growth Areas for Entrepreneurs. Business Week Online, p. 11, 2006.

GARMHAUSEN, S.; JOHNSON, E. R.; DELANEY, T. Growing a Green Business. Black Enterprise, v. 38, n. 9, p. 108, 2008.

GERLACH, A. Sustainability entrepreneurship in the context of emissions trading. Emissions Trading and Business, p. 73-87, 2006.

GLASKIN, Max. THE Big Picture for Future Sustainable Commerce. In Business, v. 26, n. 6, p. 2-2, 2004.

HARVEY, FIONA. A good time to be a green entrepreneur. Financial Times.com, 2006.

HENDRICKSON, L. U.; TUTTLE, D. B. Dynamic management of the environmental enterprise: a qualitative analysis. Journal of Organizational Change Management, v. 10, n. 4, p. 363-382, 1997.

HERON, R. Towards Reconceptualising Enterprise, Entrepreneurship and Entrepreneurial Processes for Sustainable Futures: Contributions from Economic Geography. Enterprising Worlds, p. 119-129, 2006.

HILL, T. Production/operations management: text and cases. 2. ed. New York: Prentice Hall, 1991.

IRITANI, E. A Chinese start-up tries to grow in harsh climate: Reluctant banks and other problems hinder potential. One innovative firm relies on a U.S.-based program that nurtures 'green' entrepreneurs, Los Angeles Times, 2007.

ISAAK, R. The Making of the Ecopreneur. Greener Management International, $n$. 38, p. 81-91, 2002.

JEKWA, S. Fighting HIV/Aids one wrist at a time. Finweek, v. 42, 2008.

JOHNSTON, M. Tides of Change. Forbes Asia, v. 2, n. 5, p. 20, 2006.

JONAS, $H$. Le principe responsabilité: une éthique pour la civilisation technologique. Paris: Éditions du Cerf, 1990.

JONES, S. D. The ecopreneur. Skin Diver, v. 48, n. 11, p. 13, 1999.

KAHLENBERG, R. Making an Investment in Environment of Future, Los Angeles Times, 1992.

KAMARUDDIN, A.; SAYIGH, A. A. M. Dissemination of GHE Solar Dryer in Indonesia, World Renewable Energy Congress VI, p. 2159-2162. Oxford: Pergamon, 2000. 
KATSIKIS, I. N.; KYRGIDOU, L. P. The Concept of Sustainable Entrepreneurship: A Conceptual Framework and Empirical Analysis. In: Academy of Management Proceedings, 2007.

LARSON, A. L. Sustainable innovation through an entrepreneurship lens. Business Strategy \& the Environment, v. 9, n. 5, p. 304-317, 2000.

LEE, E. Do Good, Get Rich. Black Enterprise, v. 38, n. 10, p. 72-75, 2008.

LINNANEN, L. An Insider's Experiences with Environmental Entrepreneurship. Greener Management International, n. 38, p. 71-80, 2002.

LORDKIPANIDZE, M.; BREZET, H.; BACKMAN, M. The entrepreneurship factor in sustainable tourism development. Journal of Cleaner Production, v. 13, n. 8, p. 787-798, 2005.

MARSDEN, T.; SMITH, E. Ecological entrepreneurship: Sustainable development in local communities through quality food production and local branding. Geoforum, v. 36 , n. 4, p. 440-451, 2005.

MARTINEZ, J. The New Color of Money. Publishers Weekly, v. 255, n. 21, p. 26-26, 2008.

MCDONOUGH, W.; BRAUNGART, M. Cradle to cradle: Remaking the way we make things. 1. ed. New York: North Point Press, 2002.

MERRITT, M. Green power to make Scots rich. Sunday Times, v. 20, 2001.

MINTZBERG, H. The nature of managerial work. New York: Harper \& Row,1973.

NEW REPORT 'Fueling a Greener Future' - Showcases NYC Metro Region's Commitment to Alternative-Fueled Garbage Trucks. Business Wire, 2008.

OJEDA-BENITEZ, S.; ARMIJO-DE-VEGA, C.; RAMÍREZ-BARRETO, M. E. Formal and informal recovery of recyclables in Mexicali, Mexico: Handling alternatives. Resources, Conservation and Recycling, v. 34, n. 4, p. 273-288, 2002.

PASTAKIA, A. Grassroots ecopreneurs: Change agents for a sustainable society. Journal of Organizational Change Management, v. 11, n. 2, p. 157, 1998.

POLLARD, D. Finding the sweet spot: the natural entrepreneur's guide to responsible, sustainable, joyful work. White River Junction, Vt.: Chelsea Green, 2008.

POTOCAN, V.; MULEJ, M. Entrepreneurship: Between Sustainable Development and Reality. Public Finance \& Management, v. 3, n. 2, p. 241-262, 2003.

PRAHALAD, C. K. The fortune at the bottom of the pyramid: eradicating poverty through profits. Upper Saddle River, N.J.: Wharton School Pub, 2010. 
QUINN, J. B. Next big industry: environmental improvement. Harvard Business Review, v. 49, n. 5, p. 120-131, 1971.

RAUFFLET, E.; TENGÖ, M.; GUERTIN, M.-A.; DANSOU, K.; FILION, L.J. Landscape Entrepreneurship: Lessons from the Mont Saint Hilaire Nature Centre. In: KAO, R.W.Y. (Ed.). Sustainable Economy. Corporate, Social and Environmental Responsibility. World Scientific, 2010, cap.13, p. 377-420.

ROSE, R. A. Ecopreneurs. Success, v. 37, n. 8, p. 51, 1990.

SCHALTEGGER, S. A Framework for Ecopreneurship. Greener Management International, n. 38, p. 45-58, 2002.

SCHAPER, M. Being a green entrepreneur: Does it make business sense? Businessdate, v. 13, n. 3, p. 5-7, 2005.

SCHAPER, M. The Essence of Ecopreneurship. Greener Management International n. 38, p. 26, 2002.

SEABROOK, C. Buckhead nonprofit tills green revolution Costa Rican school teaches care of Earth. The Atlanta Journal - Constitution: F.1, 2004.

SURIE, G.; ASHLEY, A. Integrating Pragmatism and Ethics in Entrepreneurial Leadership for Sustainable Value Creation. Journal of Business Ethics, v. 81, n. 1, p. 235-246, 2008.

Nation's Restaurant News, SWEDISH entrepreneur to export Meaning Green veggie concept, , v. 33, n. 42, p. 112, 1999.

THE CENTER for Economic Options: Targeting a market niche. In Business, v. 17, n. 1, p. 15, 1995.

TODD, W. Big Solar's Day In the Sun. Business 2.0, v. 8, n. 5, p. 78, 2007.

TRACEY, P.; PHILLIPS, N. The Distinctive Challenge of Educating Social Entrepreneurs: A Postscript and Rejoinder to the Special Issue on Entrepreneurship Education. Academy of Management Learning \& Education, v. 6, n. 2, p. 264-271, 2007.

UNEP. United Nations Envirnment Programme, 2006. Landmark New Report Says Emerging Green Economy Could Create Tens of Millions of New “Green Jobs”. Disponível em:

$<$ http://www.unep.org/documents. multilingual/default.asp?documentid=545\&articleid= 5929\&l=en>. Acesso em: 05 Jan 2011.

WADDOCK, S. A. The difference makers: how social and institutional entrepreneurs created the corporate responsibility movement. Sheffield, UK: Greenleaf Publishing Ltda, 2008.

RAUFFLET, E.; BRES, L.; FILION, L. J. Desenvolvimento sustentável e empreendedorismo. Revista de Empreendedorismo e Gestão de Pequenas Empresas, v. 3, n.1, p.3-32, 2014. 
WAGNER, M.; SCHALTEGGER, S. Classifying Entrepreneurship for the Public Good: Empirical Analysis of a Conceptual Framework. Journal of Small Business \& Entrepreneurship, v. 23, n. 3, p. 431-443, 2010.

WALLEY, E. E.; TAYLOR, D. W. Opportunists, Champions, Mavericks...? Greener Management International, n. 38, p. 31, 2002.

WARNOCK, J. Sustainability at the disco. Contract, v. 49, n. 3, p. 46, 2008.

WENNERSTEN, R. Sustainable Technology, Handbook of Performability Engineering, p. 919-931, 2008.

WIDE Angle Looks at a Green Entrepreneur's Carbon Credit Scheme to Fight Global Warming - and Turn a Profit. Business Wire, 2008.

YOUNG, W.; TILLEY, F. Can businesses move beyond efficiency? The shift toward effectiveness and equity in the corporate sustainability debate. Business Strategy \& the Environment, v. 15, n. 6, p. 402-415, 2006.

Artigo recebido em: 27/02/2014. Aprovado em 27/02/2014.

\section{ANEXO A: Recomendações de Choi e Gray (2008) para os EDs}

Comprometimentos ou lições:

1. Comprometa-se com um propósito significativo;

2. Seja cauteloso com o levantamento de capital institucional;

3. Contrate funcionários com valores comuns;

4. Promova os valores da sua empresa;

5. Construa uma forte cultura organizacional centrada nos valores;

6. Faça dinheiro, mas depois também faça exceções;

7. Não cause danos: Não polua, ou polua o menos possível;

8. Permaneça com a empresa por um longo período;

9. Dê bastante retorno: comprometa-se com um programa de doação;

10. Seja um modelo para os outros. 